\title{
0179 SPECIALISED JUSTICE RESPONSES TO DOMESTIC VIOLENCE CASES
}

C Gill* Correspondence: Muriel McQueen Fergusson Centre for family violence research/University of New Brunswick, 678 Windsor Street Fredericton, New Brunswick E3B 5A3, Canada

\subsection{6/ip.2010.029215.179}

One innovative justice system response, since the beginning of the nineties, has been the development of specialised domestic violence courts in different countries. These new mechanisms for dealing with cases of intimate partner violence addressed many of the identified problems of nonspecialised processes, such as improved victim services and programs for abusers, greater collaboration between family and criminal matters, and an array of new law enforcement policies and legislation, such as pro-arrest policies and domestic violence legislation. In Canada, different provincial and territorial jurisdictions have implemented specialised domestic violence courts. However, emerging research raises critical questions on the role of courts in society. Judges, defence attorneys, prosecutors and victim advocates, while expressing support for a specialised domestic violence court model, are still concerned about issues of victim safety, the safety of children, and offender recidivism. In 2007 , experts from the Canadian observatory on the justice 


\section{IP Safety 2010 abstracts}

systems response to intimate partner violence, commenced the groundwork to fully understand the process and the effectiveness of specialised domestic violence courts. In this presentation, we will discuss specialised justice responses to domestic violence cases versus non specialised responses in Canada. This will lead to talk about the importance of collaboration among diverse stakeholders in order to establish proper data collection about offenders and victims of intimate partner violence entering in the justice system. It will be an opportunity to discuss the research agenda of the Canadian observatory. 